\title{
Bioelectric Responses at Fertilization: Separation of the Events Associated With Insemination From Those Due to the Cortical Reaction in Sea Urchin, Lytechinus variegatus
}

\author{
Dieter Hülser and Gerald Schatten
}

Department of Biological Science, The Florida State University, Tallahassee

\begin{abstract}
The bioelectric responses at fertilization of the sea urchin Lytechinus variegatus are a complex series of membrane potential and resistance changes that occur concomitant with gamete fusion, ionic fluxes, and the cortical granule discharge. This work attempts to separate the electrical effects of sperm-egg interactions from those of the cortical reactions. Two approaches were taken to discern the electrical events associated with insemination, distinct from cortical granule discharge: 1) fertilization of eggs treated with $3 \%$ urethane, $10 \mathrm{mM}$ procaine, or $10 \mathrm{mM}$ nicotine, to prevent the cortical reaction and 2) refertilization of fertilized eggs (denuded with $1 \mathrm{mM}$ aminotriazole containing $1 \mathrm{mg} / \mathrm{ml}$ soybean trypsin inhibitor). Cortical granule discharge in the absence of sperm incorporation was investigated by artificial activation with $5 \mu \mathrm{M} \mathrm{A23187}$ or by fertilization in the presence of $10 \mu \mathrm{M}$ cytochalasin D, which prevents incorporation.

These results are consistent with a model in which the sperm-egg interaction triggers both a rapid $(50-400 \mathrm{msec})$, but minor ( $\cong 10 \mathrm{mV}$ ), electrical transient that leads to an action potential and then both the $\mathrm{Na}^{+}$-dependent fast block to polyspermy and the late block resulting from the secretion of the cortical granules.
\end{abstract}

Key words: fertilization, sea urchin, bioelectric response, secretion, motility

\section{INTRODUCTION}

At fertilization the sea urchin egg undergoes a complex series of electrical changes in membrane potential and resistance. The early changes include an action potential

Dr. Hülser's permanent address is Biologisches Institut, Universität Stuttgart, Ulmer Strasse 227, 7 Stuttgart 60, Federal Republic of Germany.

Received October 2, 1981, accepted January 6, 1982.

Address reprint requests to Dr. Gerald Schatten, Department of Biological Science, The Florida State University, Tallahassee, FL 32306. 
[Okamoto et al, 1977; Chambers and de Armendi, 1979] and a $\mathrm{Na}^{+}$-dependent reversal of the membrane potential [Steinhardt et al, 1971], which both together may be responsible for the fast block to polyspermy [Jaffe, 1976]. The repolarization of the membrane is accompanied by an increase in $\mathrm{K}^{+}$-conductance and by intracellular changes in $\left[\mathrm{Ca}^{++}\right]$, which trigger the metabolic activation of the egg [Steinhardt et al, 1971; Grainger et al, 1979; Steinhardt and Winkler, 1979; Shen and Steinhardt, 1980; Winkler et al, 1980].

Membrane and surface modifications occur concomitant with these electrical changes at fertilization, including the fusion of the acrosome-reacted sperm with the plasma membrane of the egg [Longo and Anderson, 1968; Schatten and Mazia, 1976] and the secretion of the cortical granules, which result in the elevation of the fertilization coat [Endo, 1961]. In this report, the separation of these two membrane events (sperm-egg membrane fusion and the secretion of the cortical granules) during fertilization was attempted, the aim being the assignment of the causality between the cellular events and the dominant bioelectric conditions of the egg at fertilization.

These results, in conjunction with the accumulated literature, support the following conclusions: 1) The membrane potential and input resistance of the unfertilized egg are in the range of $-80 \mathrm{mV}$ and $300 \mathrm{M} \Omega$ [Chambers and de Armendi, 1979; for review see Hagiwara and Jaffe, 1979], 2) voltage depolarizations of about $10 \mathrm{mV}$ at the approximate moment of sperm-egg fusion, which shortly follows sperm attachment and is independent of sperm incorporation, 3) an action potential that is fired when this depolarization reaches its threshold level [Okamoto et al, 1977; Chambers and de Armen$\mathrm{di}, 1979$ ] , 4) the $\mathrm{Na}^{+}$-dependent membrane potential reversal that precedes the secretion of the cortical granules [Steinhardt et al, 1971] and associated capacitance changes [Jaffe et al, 1978], and 5) the repolarization of the egg membrane associated with increased $\mathrm{K}^{+}$conductance and egg activation [Steinhardt and Winkler, 1979; Shen and Steinhardt, 1980]. A model in which sperm-egg fusion results in a minor electrical transient [DeFelice and Dale, 1979] and triggers the secretion of the cortical granules, which results both in the $\mathrm{Na}^{+}$-dependent fast block to polyspermy [Jaffe, 1976] and the late block due to the secreted contents of the cortical granules (Vacquier et al, 1972), is proposed.

\section{MATERIALS AND METHODS}

\section{Animal Maintenance and Gamete Preparation}

The gulf coast sea urchin Lytechinus variegatus was collected locally during the summer and fall 1979 and maintained in running sea water at the Florida State University Marine Laboratory at Turkey Point. The water temperature was raised to $24^{\circ} \mathrm{C}$ during the winter months to maintain fertility. Eggs and sperm were obtained by intracoelomic injection of $0.5 \mathrm{M} \mathrm{KCl}$. Eggs were collected and gently stirred in Millipore filtered $(0.22 \mu \mathrm{m})$ sea water at room temperature no longer than $8 \mathrm{hr}$. Dejellying was accomplished by vigorous pipetting through a fine bore pipette. Sperm were collected "dry" on ice and diluted in Millipore filtered sea water immediately before insemination.

\section{Electrophysiological Measurements}

Electrophysiological measurements were performed under a Zeiss phase contrast microscope $(16 \times$ objective $)$ and with a Leitz micromanipulator. Eggs to be impaled were freely floating, sticking spontaneously to plastic Petri dishes or immobilized on polylysine-coated glass slides or plastic Petri dishes [Mazia et al, 1975]. Microelectrodes 
were pulled with a vertical pipette puller (David Kopf Instruments) using Hilgenberg glass (Hilgenberg, West Germany, outer diameter $1 \mathrm{~mm}$, with an inner filament), and filled with $3 \mathrm{M} \mathrm{KCl}$ immediately prior to use. Electrode resistances were usually about $40 \mathrm{M} \Omega$ in seawater and were continuously compensated by bridge adjustment with 0.1 or $1 \mathrm{msec}$ pulses when membrane resistances were measured with $1 \mathrm{sec}$ pulses [Brennecke and Lindemann, 1971]. Selected eggs were impaled by momentarily vibrating the microelectrode either electrically by overtuning the negative capacitance compensation or mechanically by a jolt to the micromanipulator. Potential differences and membrane resistance were measured with the Intracellular-Preamp-Clamp Model 8500 (Dagan Corp., Minneapolis, MN) and recorded with a Beckman strip chart recorder, a Tektronix 564 storage oscilloscope, and a Mnemotron tape recorder.

\section{Sperm Incorporation in the Absence of a Cortical Reaction}

To study the electrical events associated with sperm-egg fusion and incorporation in the absence of a cortical granule discharge, two different approaches were taken, ie, insemination of eggs that had been treated with inhibitors to prevent secretion and refertilization of previously fertilized eggs. Secretion was inhibited by treating unfertilized eggs with $3 \%$ urethane (ethyl carbonate) in sea water for more than $3 \mathrm{~min}$ [Longo and Anderson, 1970b], $10 \mathrm{mM}$ procaine $\mathrm{HCl}$ in sea water ( $\mathrm{pH} 8.1$ ) for $15 \mathrm{~min}$ [Vacquier and Brandriff, 1975], or $10 \mathrm{mM}$ nicotine $\mathrm{HCl}$ in sea water $(\mathrm{pH} 8.1)$ for $15 \mathrm{~min}$ [Hägstrom and Allen, 1956; Longo and Anderson, 1970a]. Refertilization was accomplished by first fertilizing the eggs in the presence of $1 \mathrm{mg} / \mathrm{mg}$ soybean trypsin inhibitor (Sigma Chemical Co., St. Louis, MO), which prevents the hydrolytic activity of the cortical granule protease [Vacquier et al, 1972], and in $1 \mathrm{mM} \mathrm{3-amino-1,2,4-triazole} \mathrm{to}$ prevent the hardening of the elevating fertilization coat [Showman and Foerder, 1979]. The fragile fertilization coats were stripped from the now-fertilized eggs by gently pipetting through a fine bore pipette, and refertilization was then possible.

\section{Cortical Reaction in the Absence of Sperm Incorporation}

The discharge of the cortical granules was separated from sperm incorporation by two different methods, ie, artificial activation with an ionophore for divalent cations, A23187 (5 $\mu \mathrm{M}$ ) [Chambers et al, 1974; Steinhardt and Epel, 1974; Steinhardt et al, 1977] and fertilization of eggs treated with $10 \mu \mathrm{M}$ cytochalasin D, which cannot incorporate the spermatozoon [Schatten and Schatten, 1980; 1981; reviewed by Schatten, 1982]. To fully evaluate the relations between the motility necessary for the successful completion of fertilization and the electrical events, $1 \mu \mathrm{M}$ colcemid, a microtubule inhibitor that prevents the pronuclear migrations [Zimmerman and Zimmerman, 1967; Schatten and Schatten, 1981], was also employed.

\section{RESULTS \\ Studies on Control Eggs}

Membrane-potential and resistance of the unfertilized egg. Unfertilized eggs of Lytechinus variegatus can be clearly separated into two groups on the basis of measurements of their membrane potentials: i) On polylysine-coated dishes or on dishes wiped with paper tissues (Kimwipes) the adhering eggs had potential differences of about -20 $\mathrm{mV}$ and membrane input resistances of about $50 \mathrm{M} \Omega$, and ii) a small proportion of the eggs will spontaneously adhere to untreated plastic dishes; in some of these attached 
TABLE 1. Potential Differences and Membrane Resistances of "Leaky" Eggs Before, During, and After Fertilization (mean $\pm \mathbf{S E}, \mathbf{n}=\mathbf{3 5}$ )

\begin{tabular}{|c|c|c|c|c|c|c|c|}
\hline \multicolumn{2}{|c|}{$\begin{array}{l}\text { Unfertilized egg } \\
\text { mV M } \Omega\end{array}$} & \multicolumn{2}{|c|}{$\begin{array}{c}\text { Reversed potential peak } \\
\mathrm{mV} \mathrm{M} \Omega\end{array}$} & \multicolumn{2}{|c|}{$\begin{array}{c}\text { Second plateau } \\
\mathrm{mV} \mathrm{M} \Omega\end{array}$} & \multicolumn{2}{|c|}{$\begin{array}{c}\text { Final plateau } \\
\mathrm{mV} \mathrm{M} \Omega\end{array}$} \\
\hline $\begin{array}{r}-18.33 \\
\pm 1.19\end{array}$ & $\begin{array}{r}56.33 \\
\pm 1.27\end{array}$ & $\begin{array}{r}9.26 \\
\pm 0.79\end{array}$ & $\begin{array}{r}10.47 \\
\pm 1.16\end{array}$ & $\begin{array}{r}-25.10 \\
\pm 2.02\end{array}$ & $\begin{array}{r}37.00 \\
\pm 5.28\end{array}$ & $\begin{array}{r}-66.53 \\
\pm 1.97\end{array}$ & $\begin{array}{r}15.20 \\
\pm 3.22\end{array}$ \\
\hline
\end{tabular}

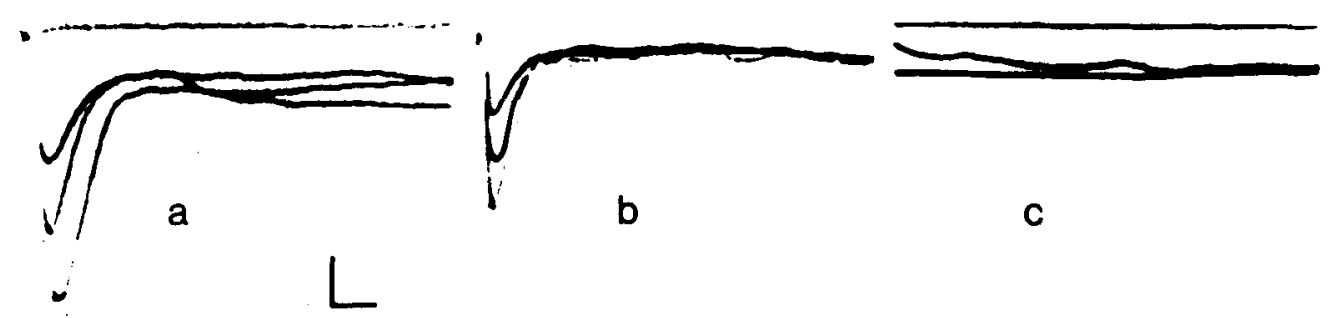

Fig. 1. Registration of potential changes during impalement of unfertilized Lytechinus variegatus eggs with glass microelectrodes. (a) Three different eggs, upper trace indicates baseline. (b) Three subsequent insertions of the same electrode into the same egg. The greatest deflection $(-35 \mathrm{mV})$ resulted from the last impalement. Point indicates baseline. (c) One minute after impalement the recorded potential difference was $-10 \mathrm{mV}$ (lower trace; upper trace = baseline). Insertion of second electrode (middle trace) led to a minor depolarization, no initial deflection detectable. Horizontal bar: $0.5 \mathrm{msec}$ in (a) and $1 \mathrm{msec}$ in (b) and (c). Vertical bar: $10 \mathrm{mV}$.

eggs potential differences of $-82 \pm 2.7 \mathrm{mV}$ (mean $\pm \mathrm{SE}, \mathrm{n}=14$ ) with input resistances from 100-500 M $\Omega$ were measured, while the remainder of these spontaneously sticking batches displayed potential differences around $-20 \mathrm{mV}$. By injection of hyperpolarizing current, the membrane potentials of some of the $-20 \mathrm{mV}$ eggs could be converted into the higher potential difference as described by Chambers and de Armendi [1979].

Several hundred potential difference measurements of the first group have been made, and in Table 1, 35 eggs, where potential and resistance measurements before, during, and after fertilization have been recorded, are tabulated. In these eggs, at higher time resolution, it is found that within $<0.5 \mathrm{msec}$ after electrode insertion the registered potential difference changes may be as high as $-80 \mathrm{mV}$ and these vary considerably from one impalement to the next. In every case, however, a stable potential difference of -10 to $-30 \mathrm{mV}$ is then recorded for hours. During this time the membrane input resistance will often increase to about $100 \mathrm{M} \Omega$. At times changes to higher membrane input resistances $(300 \mathrm{M} \Omega)$ are often accompanied by an increase in the measured membrane potential to up to $-80 \mathrm{mV}$. Figure la shows three impalements of different eggs with initial potential difference recordings between -30 and $-70 \mathrm{mV}$ which stabilized between -10 and $-20 \mathrm{mV}$ by $3 \mathrm{msec}$. Three subsequent impalements (within $1 \mathrm{~min}$ ) of one egg with the same electrode led to different initial potential difference recordings but these stabilized at the same level, eg, $-5 \mathrm{mV}$ (Fig. 1b). The last impalement led to the highest initial deflection, indicating a rapid sealing and recovery of the membrane after electrode withdrawal. When a second electrode was inserted into a previously impaled egg (Fig. 1c), no initial deflection in the potential difference was observed; the potential difference of $-10 \mathrm{mV}$ was only slightly reduced after the second impalement. 


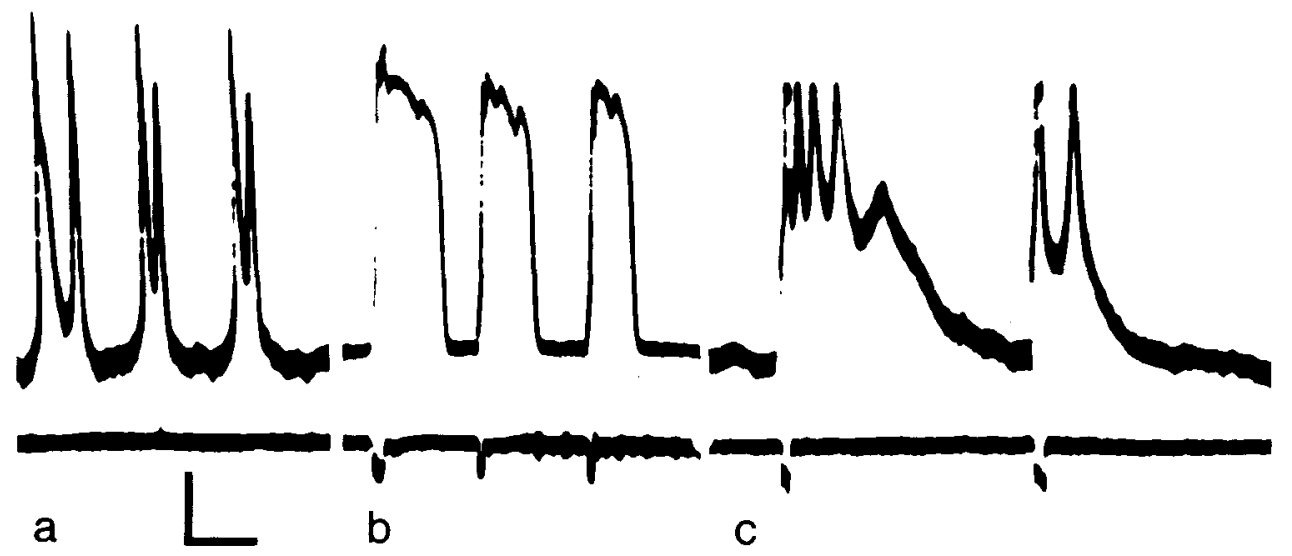

Fig. 2. Action potentials in unfertilized L variegatus eggs. (a) Spontaneous firing at threshold level, 40 $\mathrm{mV}$. (b) Electrically stimulated at a potential difference of $-72 \mathrm{mV}$. (c) Electrically stimulated at a potential difference of $-55 \mathrm{mV}$. Lower trace: record of injected current. Horizontal bar: $5 \mathrm{sec}$ in (a) and (b); $2 \mathrm{sec}$ in (c). Vertical bar: $10 \mathrm{mV}$ in (a) and (c); $20 \mathrm{mV}$ in (b); $0.5 \mathrm{nA}$ in (b) and (c) for the lower trace.

Action potentials in unfertilized eggs. Most of the $-80 \mathrm{mV}$ eggs, ie, the group with the higher potential difference level, were electrically excitable and produced action potentials that varied in shape and duration for different eggs. Three examples are shown in Figures $2 \mathrm{a}-\mathrm{c}$. Action potentials occurred spontaneously at the threshold level (eg, $-40 \mathrm{mV}$, Fig. $2 \mathrm{a}$ ) or could be electrically induced by applying depolarizing current at higher potential difference levels. The excitability of a low potential difference egg could easily be tested by transiently shifting the potential difference to higher values by injecting hyperpolarizing current. Excitable eggs fired an action potential when the hyperpolarizing current was switched off and the action potential threshold was passed. Furthermore, potential difference recordings from eggs that subsequently were found to have a long-lasting action potential always started with positive values after impalement; the negative capacitance compensation, used for impalement, masked the initial depolarizing part of the action potentials.

Fertilization potentials. Fertilization potentials, ie, the electrical events following sperm-egg attachment and probably triggered by the initial sperm-egg fusion, are clearly influenced by the electrically excitable or nonexcitable state of the unfertilized egg. Following sperm attachment to nonexcitable eggs, rapid potential changes were observed from $-80 \mathrm{mV}$ to values between -20 and $-5 \mathrm{mV}$ with potential reversal to $+20 \mathrm{mV}$. In excitable eggs sperm attachment and the ensuing fusion action potentials were fired when the threshold was attained. In Figures $3 a$ and $3 b$ two different sperminduced potential changes can be seen. For comparison, the electrically induced action potential of the egg in Figure $3 \mathrm{~b}$ while still in the unfertilized state is shown in Figure 3c. In Figures $3 \mathrm{~d}$ and $3 \mathrm{e}$, a long-lasting action potential appears to cover the early electrical events in the egg triggered by the sperm, which can clearly be resolved after short action potentials (Figs. $3 \mathrm{f}$ and $3 \mathrm{~g}$ ). Following sperm attachment and apparent fusion in an egg with a potential of $-15 \mathrm{mV}$ a step-like depolarization occurs, the amplitude of which is dependent on the input resistance (Fig. 3h). Eggs with measured potential differences of about $-10 \mathrm{mV}$ will undergo normal fertilization and cleavages. Figure $3 \mathrm{i}$ shows the 

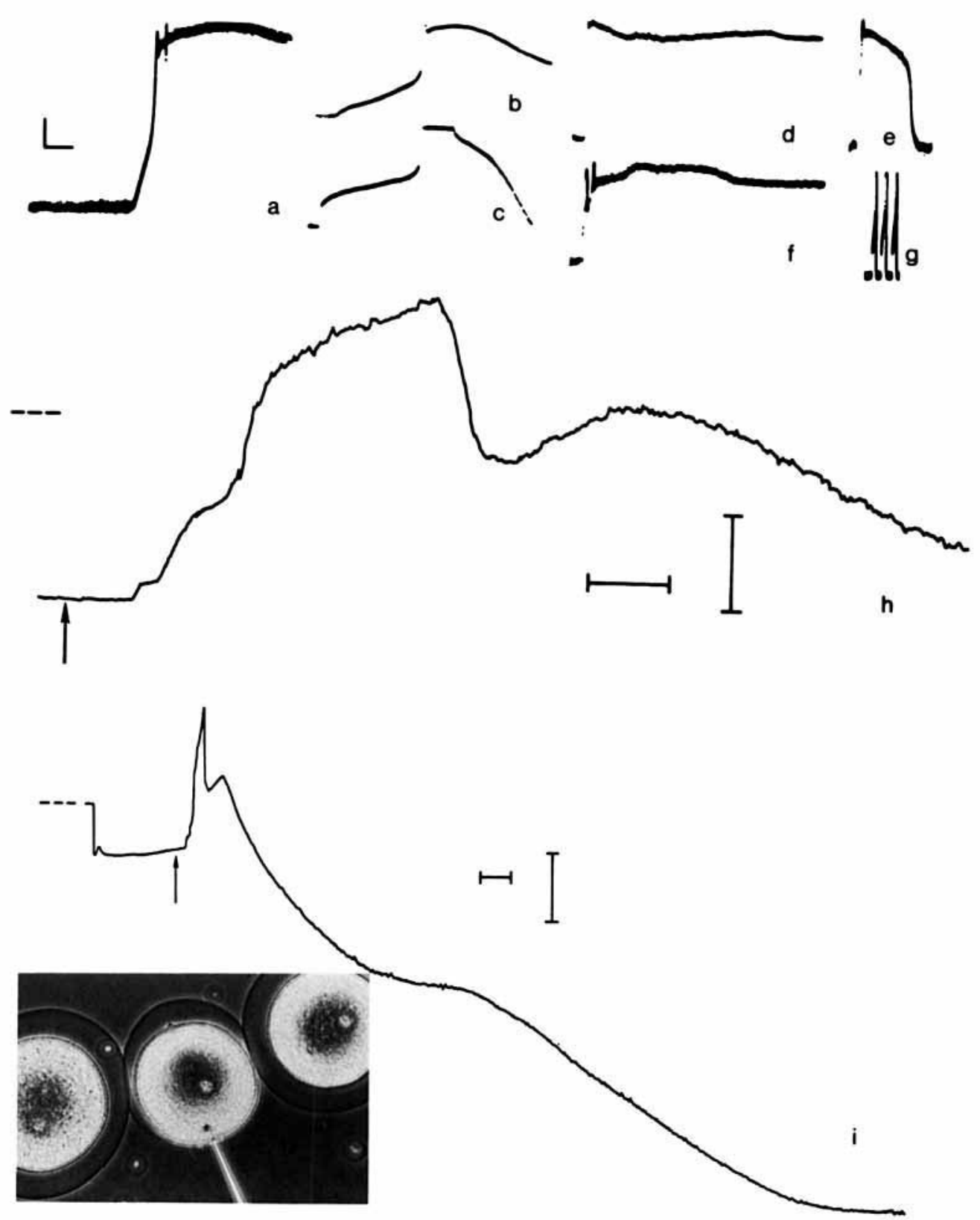

Fig. 3. Fertilization potentials in L variegatus eggs. (a) High time resolution of the initial slope of a spermegg fusion and induced-action potential in a $-64 \mathrm{mV}$ egg. (b) High time resolution of the initial slope of a sperm-egg fusion and induced action potential in a $-84 \mathrm{mV}$ egg. (c) For comparison: electrically induced action potential of egg (b), $30 \mathrm{sec}$ before fertilization. (d) Fertilization at $-85 \mathrm{mV}$. (e) Same egg as (d), electrically induced action potential. (f) Fertilization at $-79 \mathrm{mV}$. (g) Same egg as (f), electrically induced action potential. (h) Fertilization at $-19 \mathrm{mV}$; dashed line = baseline (zero). (i) Fertilization at $-8 \mathrm{mV}$; dashed line $=$ baseline (zero). Inset: developing fertilization coat after sperm-egg fusion. Horizontal bar: $0.1 \mathrm{sec}$ in (a), (b), and (c); $5 \mathrm{sec}$ in (d), (e), (f), and (g); $10 \mathrm{sec}$ in (h); $1 \mathrm{~min}$ in (i). Vertical bar: $20 \mathrm{mV}$ in (b), (c), (d), (e), (f), and (g); $10 \mathrm{mV}$ in (a), (h), and (i). 
changes in membrane potential after fertilization of an $-8 \mathrm{mV}$ egg. After sperm-egg attachment and perhaps fusion, indicated by a $2 \mathrm{mV}$ step [Dale et al, 1978], the potential reverses with a step to positive values and reaches a peak of about $+19 \mathrm{mV}$ before repolarization. Another plateau is reached at about $-25 \mathrm{mV}$, before the final potential of about $-70 \mathrm{mV}$ is measured. These membrane-potential changes are accompanied by changes in membrane resistance. The initial resistance change after sperm-egg fusion appears to depend on the sealing of the electrode. At the positive peak the input resistance is only about $10 \mathrm{M} \Omega$ and increases with the second positive peak or the first plateau to about $35 \mathrm{M} \Omega$; it remains at this level until it is gradually reduced to about 15 $\mathrm{M} \Omega$ at the final $-70 \mathrm{mV}$ plateau (see Table 1 ).

\section{Sperm Incorporation Without Cortical Granule Discharge}

In an attempt to clarify which of the potential changes are associated with cortical granule discharge, the addition of several drugs that inhibit the secretion of the cortical granules was performed.

Effects of urethane. Treatment of the eggs with 3\% urethane prevents the cortical granule secretion without activating the egg, as shown by Longo and Anderson [1970a] in Arbacia eggs. Depending on the duration of treatment and varying with animals, urethane-treated eggs formed fertilization cones upon addition of sperm (Fig. 4a, inset), which were not accompanied by the formation of a fertilization coat. Addition of urethane to impaled eggs decreases the potential difference by $30 \mathrm{mV}$ associated with the firing of an action potential if the threshold level is exceeded. In urethane an excitable egg loses its excitability. The input resistance is also reduced to about $60 \mathrm{M} \Omega$. Addition of sperm to these eggs results in transient depolarizations each with an amplitude of $25 \mathrm{mV}$; a second sperm entry could be resolved. Since the block to polyspermy is impaired, supernumerary sperm-induced potential changes can be repeated in the same egg (Fig. 4a). Fifteen minutes after replacement of the medium with fresh sea water, unfertilized eggs could be fertilized and activated with fertilization coat formation and accompanying fertilization potentials indicating a rapid recovery from the urethane effects. It is noteworthy that urethane-treated eggs did not elevate fertilization coats when $5 \mu \mathrm{M}$ A23187 was added.

Effects of nicotine and procaine. Similarly, $10 \mathrm{mM}$ nicotine or $10 \mathrm{mM}$ procaine inhibits the discharge of the cortical granules after sperm entry, although unfertilized eggs treated with these substances are artificially activated, perhaps because of a shift in internal pH [Johnson et al, 1976; Vacquier and Brandriff, 1975]. After exposure periods of $30 \mathrm{~min}$, the eggs normally display a membrane potential of $-70 \mathrm{mV}$ and a low input resistance of about $10 \mathrm{M} \Omega$. Following insemination of these eggs, fertilization cones could clearly be detected and were always preceded by transient depolarizing steps (Figs. $4 \mathrm{~b}$ and $4 \mathrm{c}$ ); hyperpolarizing steps were noted at the time of fluid addition (Figs. $4 \mathrm{c}$ and $4 \mathrm{~d}$ ). Fertilization coats failed to elevate (Figs. $4 \mathrm{~b}$ and $4 \mathrm{c}$, insets), an indication of the absence of the cortical reaction.

Effects of refertilization. Membrane potential measurements were also made on eggs refertilized $15 \mathrm{~min}$ after the fertilization coats were removed. As is characteristic of eggs at this stage of development, the membrane potential was $-70 \mathrm{mV}$, the input resistance was low, and the eggs were electrically inexcitable. The transient depolarizations observed following sperm attachment are quite similiar to those described for nicotine- and procaine-treated eggs; multiple fertilization cones were also noted (Fig. 4d). 
a
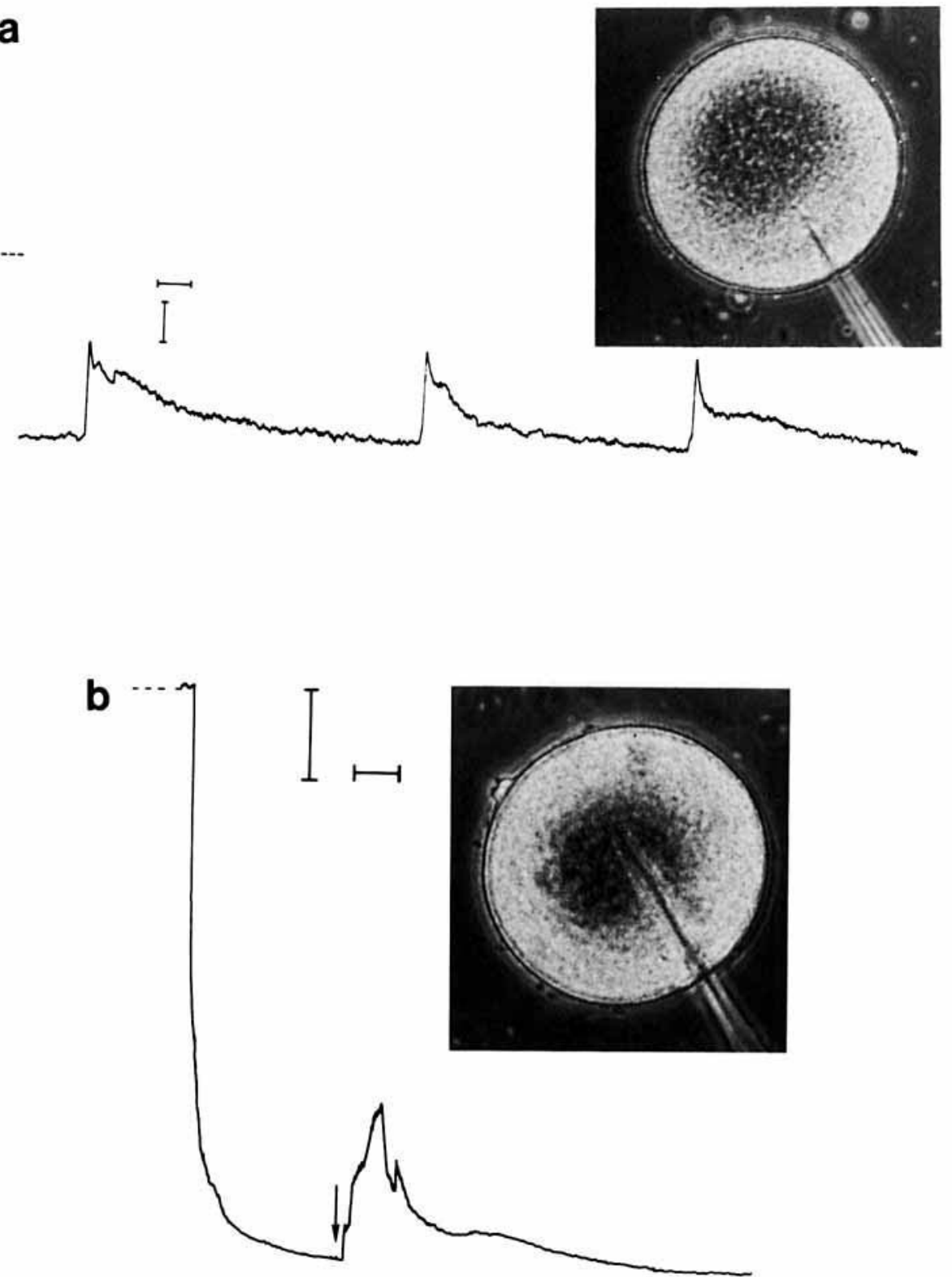

Fig. 4. Changes in potential difference upon sperm-egg fusion in the absence of cortical granule discharge and phase contrast pictures of the observed sperm entry cones. (a) $-45 \mathrm{mV}$ egg in $3 \%$ urethane. (b) -63 $\mathrm{mV}$ egg in $10 \mathrm{mM}$ nicotine. (c) $-51 \mathrm{mV}$ egg in $10 \mathrm{mM}$ procaine. (d) $-51 \mathrm{mV}$ egg in $1 \mathrm{mM}$ amino-triazole + $1 \mathrm{mg} / \mathrm{ml}$ soybean trypsin inhibitor, refertilization. Arrows indicate addition of sperm. Horizontal bar: 10 sec in (a); 1 min in (b), (c), and (d). Vertical bar: $10 \mathrm{mV}$. Dashed line: Baseline (zero). 

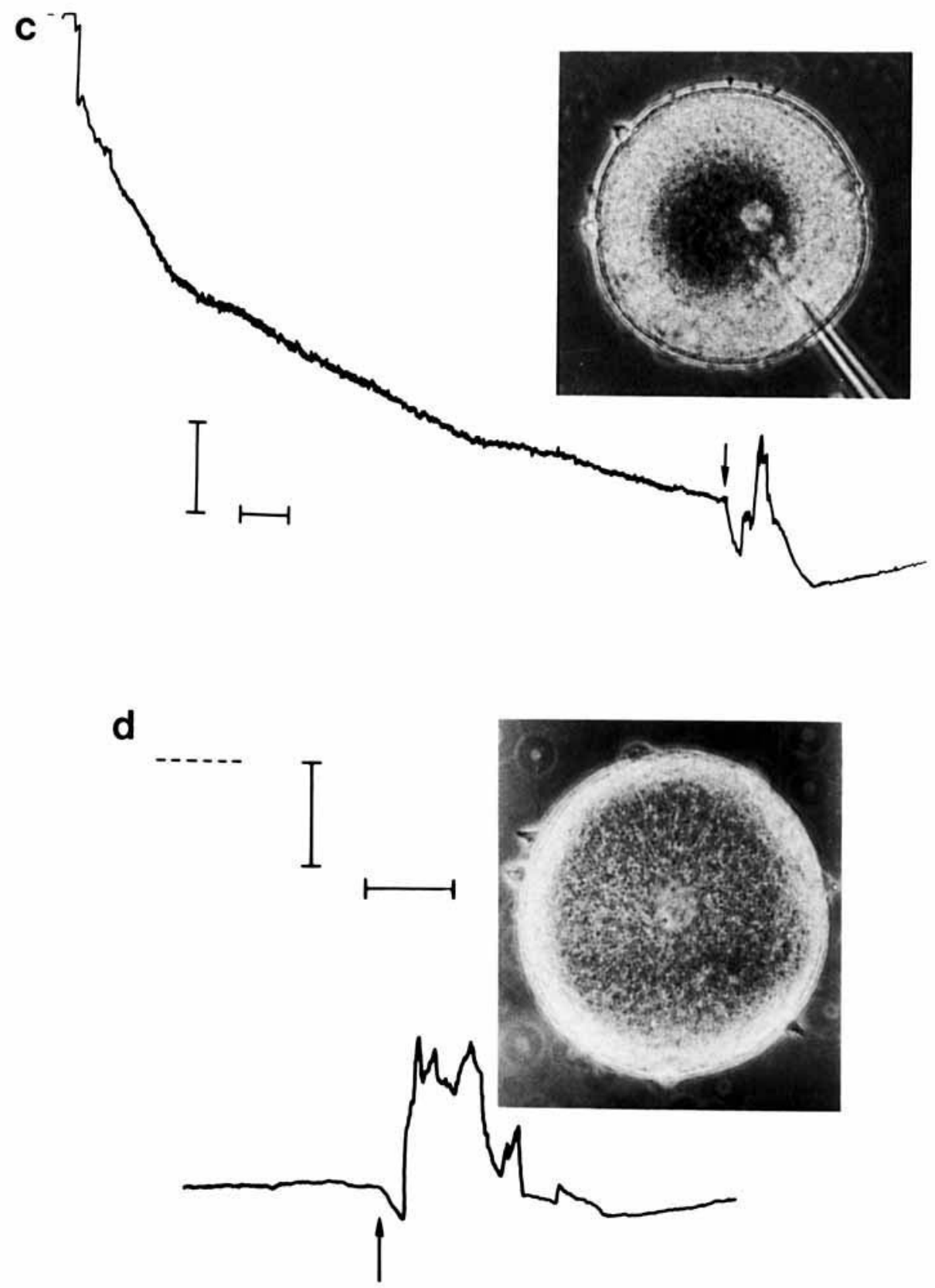

Figure 4 . 


\section{Cortical Reaction in Absence of Sperm Incorporation}

Effects of A23187. In a different approach, to investigate the role of sperm in triggering the fertilization potential, the cortical granule discharge was artificially induced by the release of intracellular $\mathrm{Ca}^{++}$following the addition of $5 \mu \mathrm{M} \mathrm{A23187}$. As can be seen from Figure 5a, the addition of ionophore results in a depolarization of the $-55 \mathrm{mV}$ egg. At the threshold level of $-45 \mathrm{mV}$, three short action potentials were fired. These action potentials are similar to those electrically induced in the same eggs prior to fertilization. These are shown at the beginning of the trace of Figure 5a. A potential reversal with a peak at $+6 \mathrm{mV}$ occurred, a "fertilization" coat developed, and 18 min later a stable plateau of $-78 \mathrm{mV}$ was reached.

Effects of cytochalasin and colcemid. In eggs treated with cytochalasin $\mathrm{D}$, a microfilament inhibitor, sperm incorporation cannot occur, even though insemination initiates the cortical granule discharge [Schatten and Schatten, 1980]. The potential reversal and fertilization coat elevation are similar to controls as is demonstrated in an egg with high membrane potential incubated in $10 \mu \mathrm{M}$ cytochalasin D (Fig. 5; Dale and De Santis, 1981]. The microtubule inhibitor, colcemid $(1 \mu \mathrm{M})$, does not affect the electrical events at fertilization (Fig. 5c). These observations indicate that the inhibition of motility at fertilization [Schatten and Schatten, 1981] does not have any bioelectric consequences.

\section{DISCUSSION}

The cellular events that correlate with the bioelectric responses and the true, as opposed to measured, electrical changes at fertilization are still not fully elucidated. There appears to be a natural variability among different animals, among species, and

a

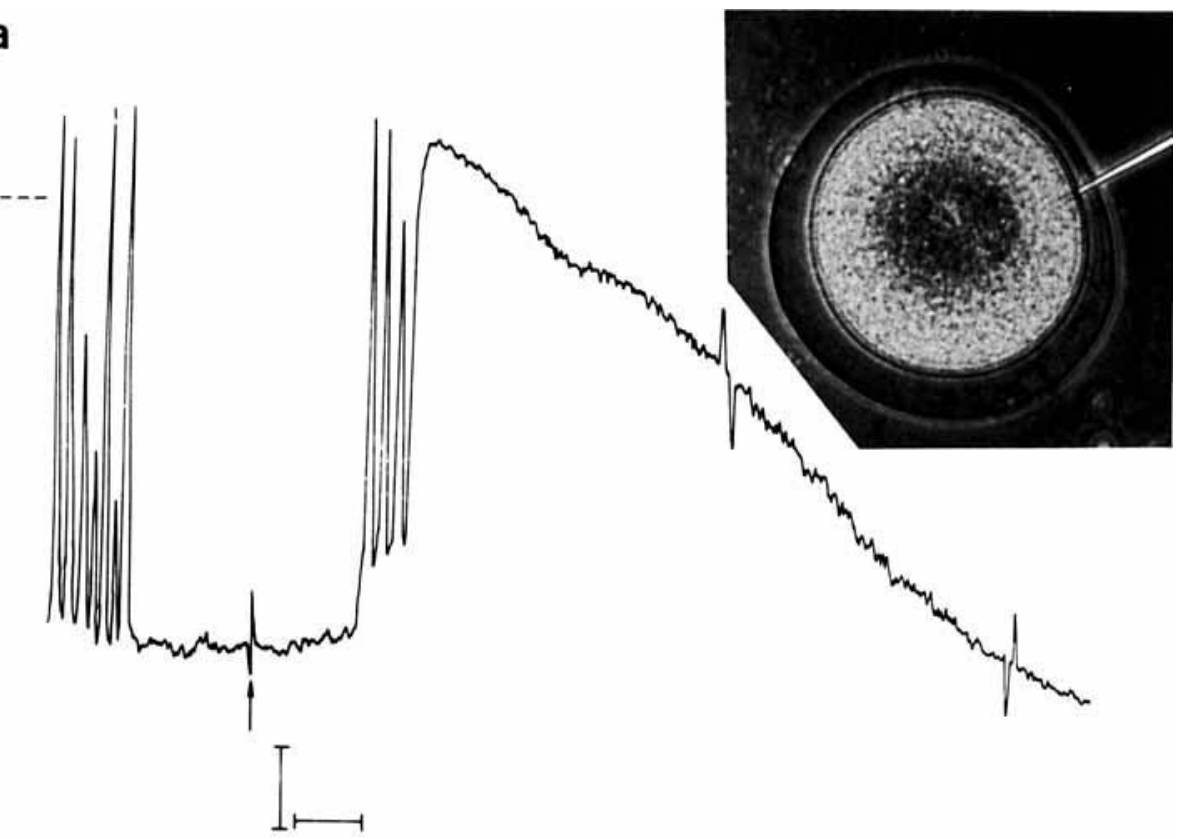



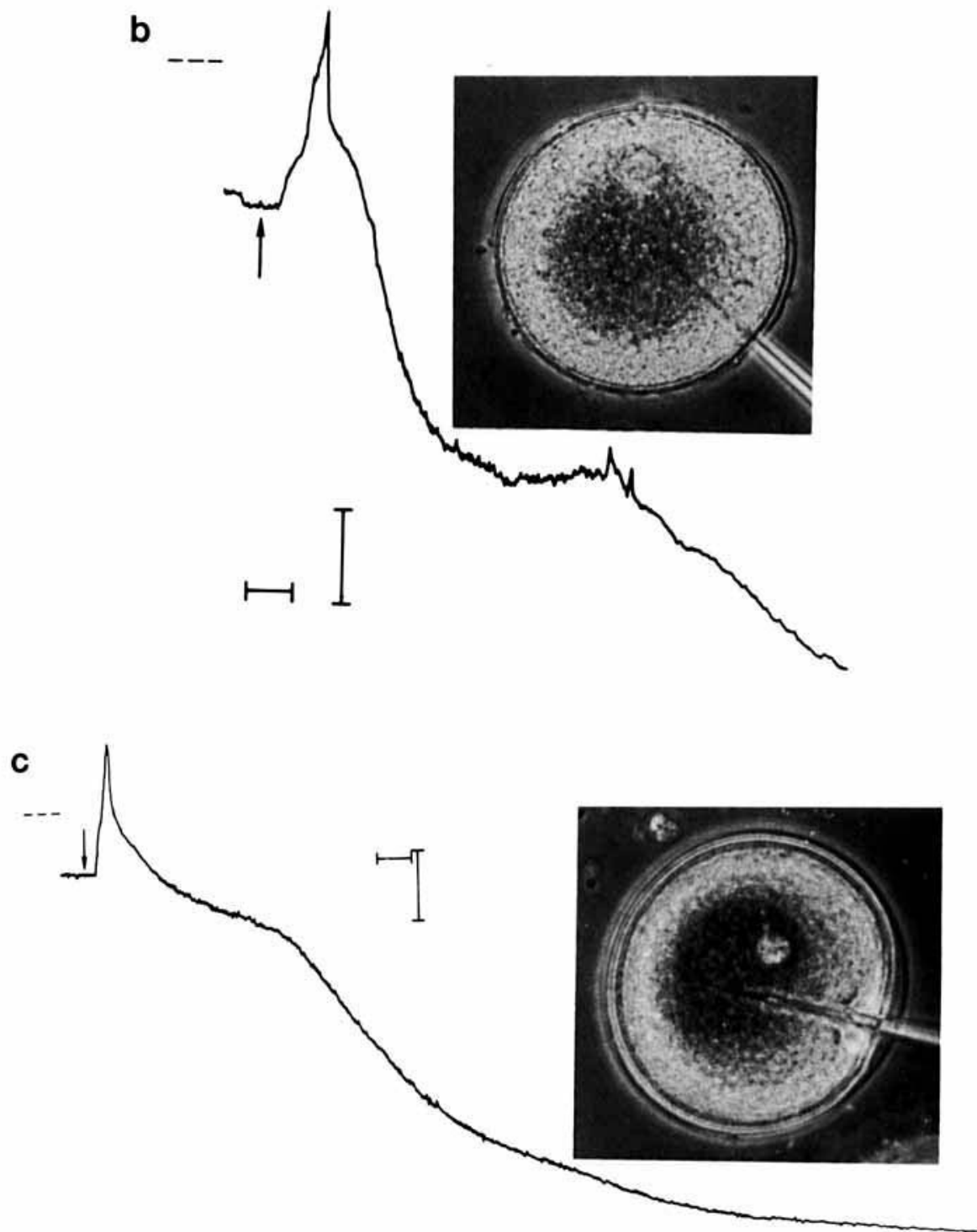

Fig. 5. Changes in potential differences upon cortical granule discharge in the absence of sperm incorporation and phase contrast pictures of the observed "fertilization" coats. (a) An excitable $-54 \mathrm{mV}$ egg and addition of $5 \mu \mathrm{M} \mathrm{Ca}^{++}$ionophore A23187. (b) A $-15 \mathrm{mV}$ egg in $10 \mu \mathrm{M}$ cytochalasin D and addition of sperm. (c) A $-10 \mathrm{mV}$ egg in $1 \mu \mathrm{M}$ colcemid and addition of sperm. Arrows indicate addition of ionophore or sperm. Horizontal bar: $10 \mathrm{sec}$ in (a), $1 \mathrm{~min}$ in (b) and (c). Vertical bar: $10 \mathrm{mV}$. A $-15 \mathrm{mV}$ egg in $10 \mathrm{mM}$ cytochalasin $\mathrm{D}$ and addition of sperm.

over the gravid season, but this cannot be the reason for the reported large differences in membrane potential measurements [Chambers and de Armendi, 1979; Dale and Monroy, 1981; DeFelice and Dale, 1979; Hagiwara and Jaffe, 1979; Jaffe and Robinson, 1978; Steinhardt et al, 1971]. There is more likely an artificial variability, caused by differences in methods of preparation and cell adhesion, which leads to a selection of 
eggs with special properties. The reason for the differences in measured membrane potentials most probably must be accounted for by a nonlinear steady-state current voltage relationship [see Hagiwara and Jaffe, 1979] and the high input resistance of the egg, which makes the recorded value of an electrode impalement strongly dependent on leakage. A leak in an egg with a nonlinear steady-state current voltage relation could either be minor, so that the recorded potential difference remains close to the membrane potential of 170 to $180 \mathrm{mV}$ or with only a slight increase in leakage the recorded potential difference will drop to values around $115 \mathrm{mV}$. It can be seen that the initial potential difference after insertion of the electrode by a jolt during the first $0.5 \mathrm{msec}$ is considerably higher, ie, 170 to $180 \mathrm{mV}$, than the "leak-potential" that is recorded after $3 \mathrm{msec}$, ie, 115 to $120 \mathrm{mV}$. From the decay curves, membrane potentials have been estimated by Chambers and Armendi [1979] according to the method of Lassen et al [1971], and it appears clear that the true membrane potential is certainly closer to $180 \mathrm{mV}$ than to 110 $\mathrm{mV}$, as previously concluded [Jaffe and Robinson, 1978]. This "leak potential" may vary from egg to egg (see Fig. 1a) but is rather stable in individual eggs.

With the exception of the first 1 to $3 \mathrm{sec}$, eggs with a "leak potential," ie, -15 to $-20 \mathrm{mV}$ eggs, will undergo fertilization with potential and resistance changes similar to those of eggs with a potential close to the expected membrane potential and both impaled groups will develop normally [Steinhardt et al, 1971]. These eggs could be used for the investigation of electrical processes, which start a few seconds after the spermegg attachment and fusion; however, they probably are not useful for investigating possible fast blocks to polyspermy [reviewed by Dale and Monroy, 1981]. After spermegg fusion, the egg membrane depolarizes to the level of its "leak potential." If this potential is already maintained in the impaled egg, only a minor potential change might be observed. Similar effects have been observed in Paracentrotus eggs by Taglietti [1979]. Following sperm-egg attachment and fusion, other later events are triggered. However, the sperm does not trigger development simply by inducing a membrane leak, since the leak set by the electrode is normally not sufficient to initiate the later events. Furthermore, the simple binding of sperm to the eggs clamped to $+5 \mathrm{mV}$ does not influence the electrical status of the egg [see also Jaffe, 1976]. The ions acquired by the sperm during the acrosome reaction [Tilney et al, 1978; Schackman et al, 1978] are likely candidates for triggering egg activation.

Membrane excitability was found in only a small percentage of the studied eggs. By clamping " $-15 \mathrm{mV}$ " eggs to $-80 \mathrm{mV}$ and recording the depolarizing off response, we could test whether an egg was excitable and assist the sealing in those eggs with a hyperpolarizing current, enabling them to regain their internally generated $-80 \mathrm{mV}$ potentials [Brown and Flaming, 1977; Chambers and de Armendi, 1979]. In most excitable eggs, the potential difference recording quickly decreased to $-80 \mathrm{mV}$ indicating a rapid sealing. In eggs with action potentials of a longer duration, the recording always started at positive values, indicating that the leak due to electrode impalement had triggered an action potential. Since action potentials vary in amplitude and duration, sperm-egg fusion processes can only be studied with the knowledge of their individual appearance, and some of the long-lasting action potentials might well be superimposed on effects related to egg activation triggered by the sperm (see Fig. 3).

After fusion of the sperm with the egg, a series of changes in the egg and in its membrane occurs [for review see Epel, 1978]. In an attempt to dissect the contribution of the different early events to the different components of the fertilization potentials, we treated the eggs with several drugs that inhibit the discharge of the cortical granules. 
These experiments resulted in eggs with membrane properties that differed from those of the unfertilized egg and that varied with different inhibitors. However, they all revealed a transient depolarization of the membrane potential after the sperm-egg interaction. This depolarization never resulted in a potential reversal and hence is clearly different from the positive shift in potential that occurs simultaneously with the cortical granule discharge. In the interpretation of these experiments, it is essential that the effects of these drugs be considered. Jaffe [1980] has studied the electrical effects of low concentrations of nicotine. However, both nicotine and procaine induce artificial activation of unfertilized sea urchin eggs [Johnson et al, 1976; Vacquier and Brandriff, 1975], with accompanying increase in potassium conductance, and urethane reduced the measured potential difference. In other electrically excitable systems, urethane and procaine have been shown to decrease sodium flux [Pichon, 1978; Weidmann, 1955], and nicotine has been shown to induce membrane depolarizations [Ginsborg and Guerrero, 1964]. The very nature of the effects of these drugs, in blocking the fusion of the cortical granule membranes with the plasma membrane, would, in itself, be expected to have bioelectric correlates, an inherent problem with the pharmacological dissection of the membrane events at fertilization.

The amplitude of these sperm-induced depolarizations depended mainly on the membrane resistance as can be seen from the small depolarization in the refertilized eggs with low resistances (Fig. 4d) and the greater depolarizations in the urethanetreated eggs with high resistances (Fig. 4a). Furthermore these eggs always allowed multiple sperm entry leading only to minor depolarizations, which were superimposed on the depolarization of a preceding sperm-egg interaction (Fig. 4a). The reciprocal experiment, namely the discharge of cortical granules without sperm interaction by the $\mathrm{Ca}^{++}$ionophore $\mathrm{A} 23187$ and without sperm incorporation by inhibition with cytochalasin $\mathrm{D}$, clearly showed that the membrane potential reversal is correlated with the cortical granule discharge, as a result of $\mathrm{Ca}^{++}$release.

Lytechinus variegatus eggs clamped to $+5 \mathrm{mV}$ cannot be fertilized, a value that is similar to that described for S. purpuratus [Jaffe, 1976]. Interestingly, sperm-egg adhesion will occur at this reversed potential. If this voltage-dependent block to fertilization becomes effective immediately upon reaching this level, eggs with action potentials will certainly have a very fast block to polyspermy, depending only on the time for depolarization until the threshold for the action potential is reached (eg, $50 \mathrm{msec}$, Fig. 3a, and $400 \mathrm{msec}$, Fig. $3 \mathrm{~b}$ ). If this action potential is long lasting, the block will be effective until the discharge of the cortical granules, which then provides a permanent block to polyspermy due to the resultant elevation of the fertilization coat. In the case of short action potentials, the potential difference repolarizes to negative values at about -10 $\mathrm{mV}$ (Fig. 3f) before the discharge of the cortical granules, thus permitting a momentary lapse in this fast block to polyspermy. However, the permanent block to polyspermy will be established, in any case, about $15 \mathrm{sec}$ after sperm-egg fusion. Since we cannot exclude the possibility that action potentials are present only in a small percentage of eggs, this permanent block may well be the most common one. The discharge of the cortical granules was followed by fertilization coat elevations that usually could be observed when the eggs started to repolarize from $+10 \mathrm{mV}$ to negative values. At this time the resistance sharply increases to $35 \mathrm{M} \Omega$, but the egg quickly repolarized to -70 $\mathrm{mV}$ and the input resistance decreased to about $20 \mathrm{M} \Omega$.

In summary, these results, and the accumulated electrophysiological knowledge, appear to support the following model for sea urchin eggs at fertilization: The unfertil- 
ized egg has a resting potential on the order of $-80 \mathrm{mV}$, with a high membrane resistance, and may well be electrically excitable. Sperm-egg attachment and fusion, but not binding or incorporation per se, results in a minor (about $10 \mathrm{mV}$ ) and rapid (50-400 $\mathrm{msec}$ ) transient, which would trigger action potentials in excitable eggs. This transient also triggers both the discharge of the cortical granules and the $\mathrm{Na}^{+}$-dependent membrane potential reversal; it is possible that the cortical reaction itself results in the opening of these $\mathrm{Na}^{+}$channels, with the later changes in capacitance [Jaffe et al, 1978] being due to a reorganization of this mosaic membrane. The fast block to polyspermy then may have two components - the fast electrical excitability of the egg and the longer $\mathrm{Na}^{+}$-dependent membrane potential reversal-while the late block is solely related to the secretion of the cortical granules. These results underscore the importance of the cortical reaction in the establishment of overlapping blocks to polyspermy.

\section{ACKNOWLEDGMENTS}

It is a pleasure to acknowledge the kind cooperation of Dr. Dexter Easton, who generously shared his laboratory facilities. The careful reviews of this manuscript by Drs. E. Chambers, L. DeFelice, D. Easton, and R. Steinhardt are gratefully acknowledged. Portions of this work were presented at the Second International Congress on Cell Biology [Hülser and Schatten, 1980]. This work was supported by grants from the National Institutes of Health (HD12913; HD00363) and the Deutsche Forschungsgemeinschaft (Hu 204/7).

\section{REFERENCES}

Brennecke R, and Lindemann B (1971): A chopped-current clamp for current injection and recording of membrane polarization with single electrodes of changing resistance. TIT J Life Sci 1:53-58.

Brown KT, Flaming DG (1977): New microelectrode techniques for intracellular work in small cells. Neuroscience $2: 813-828$.

Chambers EL, de Armendi J (1979): Membrane potential, action potential, and activation potential of eggs of the sea urchin Lytechinus variegatus. Exp Cell Res 122:203-218.

Chambers EL, Pressman BC, Rose B (1974): The activation of sea urchin eggs by the divalent ionophoresA23187 and X-537A. Biochem Biophys Res Commun 60:126-139.

Dale B, DeFelice L, Taglietti V (1978): Membrane noise and conductance increase during single sperm-egginteractions. Nature 275:217-219.

Dale B, DeSantis A (1981): Effect of cytochalasin B and D on fertilization of sea urchins. Dev Biol 83:232237.

Dale B, Monroy A (1981): How is polyspermy prevented? Gamete Res 4:151-169.

DeFelice LJ, Dale B (1979): Voltage response to fertilization and polyspermy in sea urchin eggs and oocytes. Devel Biol 72:327-341.

Endo Y (1961): Changes in the cortical layer of the sea urchin eggs at fertilization studied with the electron microscope. Exp Cell Res 25:383-397.

Epel D (1978): Mechanisms of activation of sperm and egg during fertilization of sea urchin gametes. In Moscona AA, Monroy A (eds): “Current Topics in Developmental Biology.” New York: Academic Press, vol 12, pp 185-246.

Ginsborg BL, Guerrero S (1964): On the action of depolarizing drugs on sympathetic ganglion cells of the frog. J Physiol 172:189-206.

Grainger IL, Winkler MM, Shen SS, Steinhardt RA (1979): Intracellular pH controls protein synthesis rate in the sea urchin egg and early embryo. Dev Biol 68:396-406.

Hagiwara S, Jaffe L (1979): Electrical properties of egg cell membranes. Annu Rev Biophys Bioeng 8:385416.

Hägstrom BE, Allen RD (1956): The mechanism of nicotine-induced polyspermy. Exp Cell Res 10:14-23.

Hülser D, Schatten G (1980): Bioelectric responses of sperm-egg union and the cortical reaction in the sea urchin Lytechinus variegatus, Eur J Cell Biol 22:253.

Jaffe LA (1976): Fast block to polyspermy in sea urchin eggs is electrically mediated. Nature 261:68-71. Jaffe LA (1980): Electrical polyspermy block in sea urchins: Nicotine and low sodium experiments. Dev Growth Differ 22:503-507. 
Jaffe LA, Hagiwara S, Kado RT (1978): The time course of cortical vesicle fusion in sea urchin eggs observed as membrane capacitance changes. Dev Biol 67:243-248.

Jaffe LA, Robinson KR (1978): Membrane potential of the unfertilized sea urchin egg. Dev Biol 62:215228.

Johnson J, Epel D, Paul M (1976): Intracellular pH and activation of sea urchin eggs after fertilization. Nature 262:661-664.

Lassen UV, Nielsen AMT, Pape L, Simonsen LO (1971): The membrane potential of Ehrlich Ascites tumour cells: Microelectrode measurements and their critical evaluation. J Membr Biol 6:269-288.

Longo FJ, Anderson E (1968): The fine structure of pronuclear development and fusion in the sea urchin, Arbacia punctulata. J Cell Biol 66:198-200.

Longo FJ, Anderson E (1970a): The effects of nicotine on fertilization in the sea urchin Arbacia punctulata. J Cell Biol 46:308-325.

Longo FJ, Anderson E (1970b): A cytological study of the relation of the cortical reaction to subsequent events of fertilization in urethane-treated eggs of the sea urchin, Arbacia punctulata. J Cell Biol 47:646-665.

Mazia D, Schatten G, Sale W (1975): Adhesion of cells to surfaces coated with polylysine: Applications to electron microscopy. J Cell Biol 66:198-200.

Okamoto H, Takahashi K, Yamashita N (1977): Ionic currents through the membrane of the mammalian oocyte and their comparison with those in tunicate and sea urchin. J Physiol 267:465-495.

Pichon Y (1978): Effects of urethane on the ionic currents in squid giant axons. J Physiol 287:31P-32P.

Schackman RW, Eddy EM, Shapiro BM (1978): The acrosome reaction of Strongylocentrotus purpuratus: Ion requirements and movements. Dev Biol 65:483-495.

Schatten G (1982): The movements of the nuclei at fertilization. In Zimmerman A, Forer A (eds): "Cellular Biodynamics; Mitosis and Cytokinesis." New York: Academic Press, pp 59-80.

Schatten G, Mazia D (1976): The penetration of the spermatozoon through the sea urchin egg surface at fertilization. Exp Cell Res 98:325-337.

Schatten G, Schatten H (1981): Effects of motility inhibitors during sea urchin fertilization. Exp Cell Res 135:311-330.

Schatten H, Schatten G (1980): Surface activity at the egg plasma membrane during sperm incorporation and its cytochalasin B sensitivity: Scanning electron microscopy and time-lapse video microscopy during fertilization of the sea urchin Lytechinus variegatus. Dev Biol 78:435-449.

Shen SS, Steinhardt RA (1980): Intracellular pH controls the development of new potassium conductance after fertilization of the sea urchin egg. Exp Cell Res 125:55-61.

Showman RM, Foerder CA (1979): Removal of the fertilization membrane of sea urchin embryos employing aminotriazole. Exp Cell Res 120:253-255.

Steinhardt RA, Epel D (1974): Activation of sea urchin eggs by a calcium ionophore. Proc Natl Acad Sci USA 71:1915-1919.

Steinhardt RA, Lundin L, Mazia D (1971): Bioelectric responses of the echinoderm egg to fertilization. Proc Natl Acad Sci USA 68:2426-2430.

Steinhardt RA, Winkler MA (1979): The ionic hypothesis of cell activation at fertilization. In Kaplin JG, (ed): "The Molecular Basis of Immune Cell Function." Amsterdam: Elsevier/North-Holland Biomedical Press.

Steinhardt RA, Zucker R, Schatten G (1977): Intracellular calcium release at fertilization in the sea urchin egg. Dev Biol 58:185-196.

Taglietti V (1979): Early electrical responses to fertilization in sea urchin eggs. Exp Cell Res 120:448-451.

Tilney LG, Kiehart DP, Sardet C, Tilney M (1978): Polymerization of actin. IV. Role of $\mathrm{Ca}^{++}$and $\mathrm{H}^{+}$in the assembly of actin and in membrane fusion in the acrosomal reaction of echinoderm sperm. $J$ Cell Biol 77:536-550.

Vacquier VD, Brandriff B (1975): DNA synthesis in unfertilized sea urchin eggs can be turned on and turned off by the addition and removal of procaine hydrochloride. Dev Biol 47:12-31.

Vacquier VD, Tegner MJ, Epel D (1972): Protease activity establishes the block against polyspermy in sea urchin eggs. Nature 240:352-353.

Weidmann S (1955): Effects of calcium ions and local anaesthetics on electrical properties of Purkinje fibers. J Physiol 129:568-582.

Winkler MM, Steinhardt RA, Grainger JL, Minning L (1980): Dual ionic control of the activation of protein synthesis at fertilization. Nature 287:558-560.

Zimmerman AM, Zimmerman J (1967): Action of coicemid in sea urchin eggs. J Cell Biol 34:483-488. 